\title{
Cultural and Physiological Studies on Wild Mushroom Specimens of Schizophyllum commune and Lentinula edodes
}

\author{
B. Praveen Kumar Reddy ${ }^{1}$, A. Uma Rajashekhar ${ }^{2}$, P. Harikrishna ${ }^{3 *}$ and A.V.N. Lavanya ${ }^{4}$ \\ ${ }^{1}$ Department of Horticulture, College of Horticulture, Dr. Y.S.R. Horticultural University, \\ Rajendranagar, Hyderabad, 500030, Andhra Pradesh, India \\ ${ }^{2}$ Department of Agriculture Microbiology and Bio-energy, ANGRAU, College of Agriculture, \\ Rajendranagar, Andhra Pradesh, India \\ ${ }^{3}$ Department of Agriculture Microbiology and Bio-energy, ANGRAU, Post-Harvest Technology \\ Centre, College of Agriculture, Bapatla, Andhra Pradesh, India \\ ${ }^{4}$ Department of Horticulture, College of Horticulture, Dr. Y.S.R. Horticultural University, \\ Venkataramannagudem, Andhra Pradesh, India \\ *Corresponding author
}

\section{A B S T R A C T}

Keywords

Schizophyllum commune, Lentinula edodes, Physiological studies, Culture media.

Article Info Accepted: 23 June 2017 Available Online: 10 July 2017
A study was conducted on the influence of culture media, temperature and $\mathrm{pH}$ levels on the mycelial growth of two wild specimens of Schizophyllum commune and Lentinula edodes during 2013. The results of the experiment indicated that, potato dextrose agar medium with a $\mathrm{pH}$ range of 5.0-7.0 at a temperature of $30^{\circ} \mathrm{C}$ and malt extract medium with a $\mathrm{pH}$ range of 4.5-6.5 at a temperature of $25^{\circ} \mathrm{C}$ were found optimum for the mycelial growth of $S$. commune and L. edodes, respectively. The sharp decline in the $\mathrm{pH}$ values of the liquid broth media under post mycelial growth conditions of L. edodes clearly indicated the prefer ability of the media or substrates with lower $\mathrm{pH}$. Study of lethal temperatures revealed the tropical nature of the wild strain of $S$. commune, where there was revival of the growth even after the exposure period of seven days at $45{ }^{\circ} \mathrm{C}$. The results will be helpful for the maintenance of these cultures in pure, stable and viable conditions.

\section{Introduction}

Mushrooms are increasingly being evaluated around the world for their nutritional and pharmacological properties. They are considered as functional foods as well as a source of physiologically beneficial and noninvasive medicines. Since the ancient times medicinal mushrooms have been played significant role in alleviating the health issues of human beings (Neha and Bharat, 2012). The traditional use of mushroom products has been long established among different cultural groups.

As a result of the large scale domestication of these nutritionally and medicinally important mushrooms, mushroom production became 
the second most important commercial microbial technology, next to the yeasts (Singh et al., 2000).

Different mushrooms were studied by the scientific community, in searching for new therapeutic alternatives. Some of the most recently isolated compounds from the shiitake (Martnexflores et al., 2009) and Schizophyllum (Arpita and Bhupendra, 2013) have shown promising immunomodulairty and anti-tumor effects. Presently, the interest in the use of these mushrooms as a functional food is rising, but not much advancement has been made due to the availability of less number of strains suitable to grow under controlled conditions and also lack of pure and viable cultures for spawn production at a larger scale. Periodic collections of indigenous mushroom specimens from various climatic zones of the country and their cultural and morphological characterization are necessary to avert this problem and also for the future exploitation of the beneficial compounds from the wild mushrooms. Sizable production of these mushrooms depends upon proper maintenance and production of reliable pure culture under stable and viable conditions. The morpho cultural conditions for the most efficient mycelial colonization of the wild specimens need to be standardized for their use as reference strains. Hence, the present investigation was undertaken to determine the physiological factors required for the conservation and maintenance of pure cultures of the wild specimens of Schizophyllum commune and Lentinula edodes.

\section{Materials and Methods}

The wild specimens of Schizophyllum commune and Lentinula edodes were collected in the Plant Pathology Department, College of Agriculture, Mushroom
Cultivation Scheme, Rajendranagar, Hyderabad, India and the tissue culture of the specimens were raised from sporopheres on MEA medium. These specimens were purified and cultures were deposited in the Microbiology lab at Department of Microbiology, Post-Harvest Technology Centre, College of Agriculture, Bapatla, Andhra Pradesh, India for conservation and coded as SC-1 (Schizophyllum commune) and LE-1 (Lentinula edodes).)

Various physiological factors viz., media, temperature and $\mathrm{pH}$ required for optimal vegetative growth and conservation of the cultures were evaluated. Malt Extract Agar (MEA), Potato Dextrose Agar (PDA), Potato Malt Agar (PMA), Potato Carrot Agar (PCA), Oat Meal Agar (OMA) and Raper's Complete medium (RC) containing $20.0 \mathrm{~g}$ glucose, $2.0 \mathrm{~g}$ peptone, $2.0 \mathrm{~g}$ yeast extract, $0.50 \mathrm{~g}$ magnesium sulphate, $0.46 \mathrm{~g}$ potassium dihydrogen phosphate and $20.0 \mathrm{~g}$ agar powder per liter of distilled water were used in the study as mycological media after sterilized in an autoclave at $121^{\circ} \mathrm{C}$ and 15 psi pressure for 20 minutes.

The effect of different temperatures on mycelial growth of both the wild specimens was studied by inoculating the mycelial discs of similar diameter $(8 \mathrm{~mm})$. The discs were obtained by using the sterilized punch-hole tool to cut the mycelium from the periphery of 10 days old pure culture and place it into a new sterilized medium plate by using a transplant needle. Plates were incubated separately at temperatures of $10-40{ }^{\circ} \mathrm{C}$ with an interval of $5{ }^{\circ} \mathrm{C}$ and the radial growth was recorded at $24 \mathrm{hrs}$ intervals.

To find out the optimum $\mathrm{pH}$ level, mycelia dry weight was recorded as the measure of biomass production in malt extract broth (malt extract powder $30.0 \mathrm{~g}$, peptone $5.0 \mathrm{~g}$ per liter of distilled water). The $\mathrm{pH}$ of media was 
adjusted from 3.5-9.0 (each at an interval of $0.5)$ by using $\mathrm{N} / 10 \mathrm{NaOH}$ or $\mathrm{N} / 10 \mathrm{HCl}$. Microscopic studies of the vegetative mycelium were also undertaken to study the morphological characteristics of vegetative mycelium.

The treatments were arranged in a Completely Randomized Design (CRD) with five replications for each treatment and the data on experimental observations were statistically analyzed by using software AGRES.

\section{Results and Discussion}

\section{Effect of different media on mycelial growth rate $(\mathrm{mm} / \mathrm{day})$}

Both the isolates could grow on MEA, PDA, PMA, PCA and RC medium. However, SC-1 showed significantly higher growth rate of $17.00 \mathrm{~mm}$ per day on PDA medium and LE-1 showed an average growth of $12.32 \mathrm{~mm}$ per day on MEA media which was significantly higher compared to the other mycological media (Table 1). Evaluation of culture conditions for the vegetative growth of different strains of $L$. edodes by Hem Lata and Sharma, 2012 also revealed significantly higher mycelial growth rate of $7.5 \mathrm{~mm} /$ day on MEA media. Least growth rate of 6.05 and $2.73 \mathrm{~mm}$ per day was observed in OMA media for SC-1 and LE-1 respectively. The pattern of mycelial growth of both the wild strains on PDA, PMA and MEA in petri plates were fully compact whereas, fluffy and sparse growth was observed on PCA, OMA and RC medium. Microscopic studies of the vegetative mycelium clearly showed the clamp connections at each septum which may be helpful for the future taxonomic studies of these wild specimens.

\section{Effect of pH on mycelial growth}

$\mathrm{pH}$ of the medium is important as it influences the mineral availability and enzyme activity. It is evident from the data that, $\mathrm{pH}$ range of 5.0 to 8.0 was optimum for the growth of $S$. commune, whereas $\mathrm{pH}$ range of 4.5 to 6.5 was found best for the optimum growth of L. edodes (Fig. 1). pH range of 4.07.0 was recorded optimum for the vegetative growth of $L$. edodes in the earlier studies (Tnglet et al., 2006). The exact hydrogen environment of fungi is difficult to study as fungi changes the $\mathrm{pH}$ when it grows on the media. The critical observation of $\mathrm{pH}$ values of the filtrate after fungal growth explains the above pattern.

During the mycelial growth on liquid broth media the strain SC-1 modified the $\mathrm{pH}$ of the media to the nearest optimum range from 5.47 to 6.58 (Fig. 2) which supported the best growth of the strain on the above mentioned range. The $\mathrm{pH}$ values of the liquid broth media after filtration of the biomass produced by the strain LE-1 showed an extreme acidic range of 3.11 to 3.38 (Fig. 1) which indicates the prefer ability of acidic substrates for the vegetative growth of $L$. edodes. Correlation studies of the L. edodes crop performance with the substrate properties also showed the sharp decline in the $\mathrm{pH}$ values of the substrate after incubation period in the earlier studies (Philippoussis et al., 2003).

\section{Effect of temperature on mycelial growth rate $(\mathrm{mm} / \mathrm{day})$}

The results indicated the typical tropical nature of the $S$. commune which has shown considerable measure of mycelial growth at a wide range of temperatures. It was found that the growth rate of $S$. commune was optimum (15 mm per day) at the temperature of $30{ }^{\circ} \mathrm{C}$ and the mycelia continues to grow $(1.7 \mathrm{~mm}$ per day) even at $40{ }^{\circ} \mathrm{C}$.

The growth rate was revived to $12.86 \mathrm{~mm}$ per day when the strain was shifted to the optimum temperature after 10 days exposure at $40{ }^{\circ} \mathrm{C}$ (Table 2). Based on the experimental 
findings, $25 \quad{ }^{\circ} \mathrm{C}$ was found optimum temperature for the culture maintenance of $L$. edodes where the growth rate was observed @ $8.45 \mathrm{~mm}$ per day. Studies conducted on
Malaysian strain of L. edodes showed the best growth rate of $12.85 \mathrm{~mm} / \mathrm{day}$ at a temperature of $25{ }^{\circ} \mathrm{C}$ (Sharma et al., 2006) which confirms the present findings.

Fig.1 Biomass production (Dry weight in $\mathrm{mg}$ ) at different $\mathrm{pH}$ levels

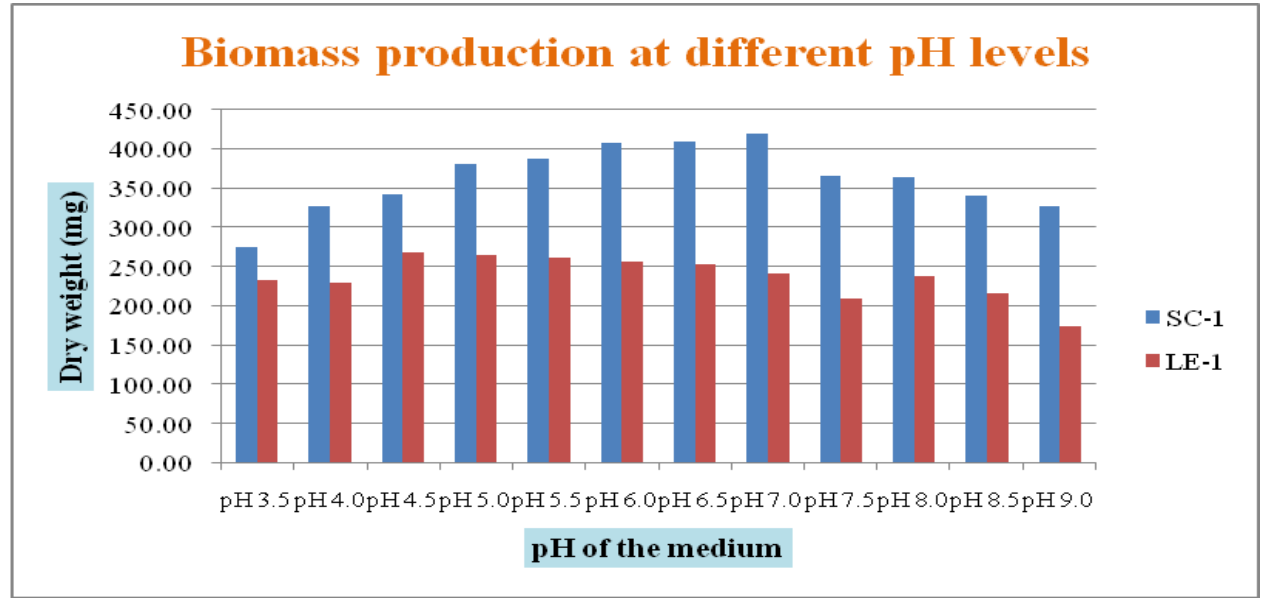

Fig.2 Post filtration $\mathrm{pH}$ values of liquid broth media

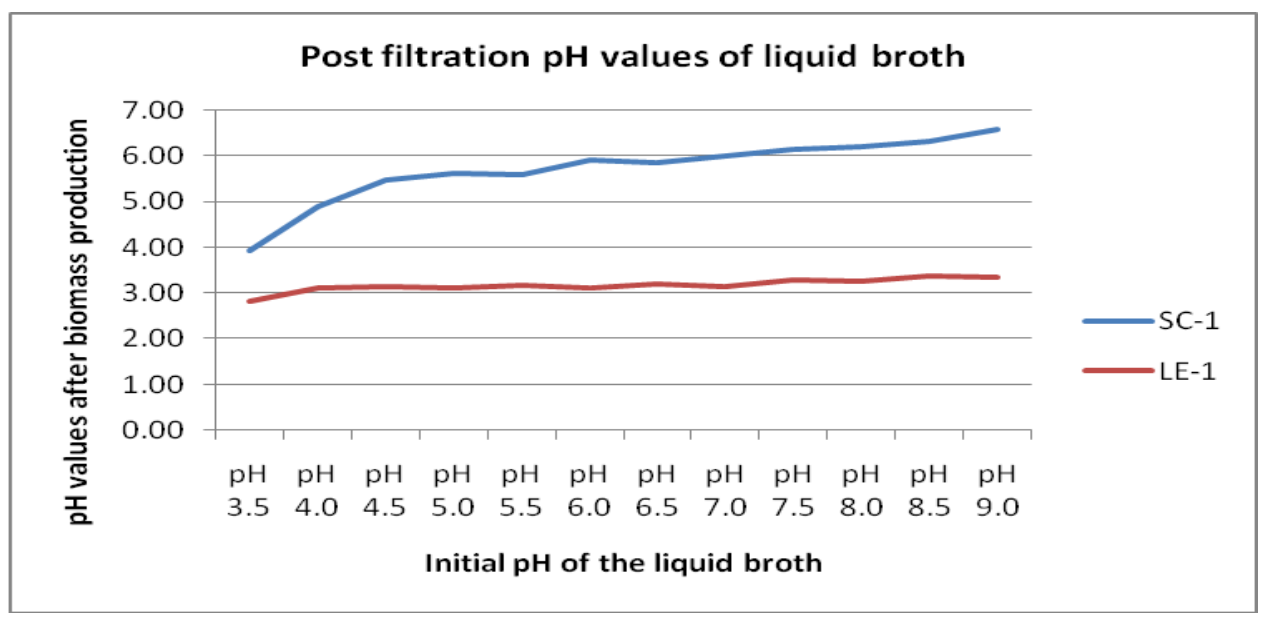

Table.1 Effect of different culture media on mycelial growth rate ( $\mathrm{mm} /$ day)

\begin{tabular}{lcc}
\hline \multicolumn{1}{c}{ Culture medium } & \multicolumn{2}{c}{ Radial mycelial growth $(\mathbf{m m} / \mathbf{d a y})$} \\
\cline { 2 - 3 } & SC-1 & LE-1 \\
\hline Oat Meal Agar & 6.05 & 2.73 \\
Potato Dextrose Agar & 17.00 & 9.67 \\
Raper's Complete medium & 14.28 & 5.30 \\
Potato Malt Agar & 14.28 & 9.33 \\
Malt Extract Agar & 14.28 & 12.32 \\
Potato Carrot Agar & 11.78 & 10.00 \\
\hline S Ed & 0.98 & 0.45 \\
CD $(0.05)$ & 2.98 & 1.39 \\
\hline
\end{tabular}


Table.2 Effect of different temperatures on mycelial growth rate ( $\mathrm{mm} /$ day)

\begin{tabular}{ccc}
\hline & \multicolumn{2}{c}{ Radial mycelial growth $(\mathbf{m m} /$ day $)$} \\
\cline { 2 - 3 } Temperature & SC-1 & LE-1 \\
\hline $10{ }^{\circ} \mathrm{C}$ & 2.31 & 2.06 \\
$15{ }^{\circ} \mathrm{C}$ & 2.43 & 2.43 \\
$20{ }^{\circ} \mathrm{C}$ & 9.67 & 6.29 \\
$25{ }^{\circ} \mathrm{C}$ & 11.25 & 8.45 \\
$30{ }^{\circ} \mathrm{C}$ & 15.00 & 5.31 \\
$35^{\circ} \mathrm{C}$ & 13.57 & No growth \\
$40{ }^{\circ} \mathrm{C}$ & 5.51 & No growth \\
\hline $\mathrm{SE} \mathrm{d}$ & 0.43 & 0.21 \\
$\mathrm{CD}(0.05)$ & 1.27 & 0.94 \\
\hline
\end{tabular}

Table.2a Lethal temperatures for the mycelial growth ( $\mathrm{mm} /$ day)

\begin{tabular}{llccc}
\hline \multirow{2}{*}{ Strain } & \multirow{2}{*}{ Temperature } & \multicolumn{3}{c}{ Exposure interval } \\
\cline { 3 - 5 } & & $\mathbf{7 ~ d a y s}$ & $\mathbf{1 4}$ days & 21 days \\
\hline $\mathrm{SC}-1$ & $45^{\circ} \mathrm{C}$ & $8.45(\mathrm{~mm} /$ day $)$ & No growth & No growth \\
$\mathrm{LE}-1$ & $38^{\circ} \mathrm{C}$ & No growth & No growth & No growth \\
\hline
\end{tabular}

\section{Study of lethal temperature}

Along with the optimum growth rate at different temperatures, studies were undertaken to examine the maximum temperature tolerance limits and lethal temperature of both the wild strains and the results presented vide (Table 2a). The strain $\mathrm{SC}-1$ was exposed to the maximum temperature of $45^{\circ} \mathrm{C}$ and later temperature was altered to the optimum range of $30^{\circ} \mathrm{C}$ after 7, 14 and 21 days of exposure period. The results clearly indicated that, the strain can tolerate the maximum temperature of $45^{\circ} \mathrm{C}$ up to 7 days and revived the growth to normal conditions (9 $\mathrm{mm}$ per day), whereas exposure period 14 days found to be lethal as there was no revival of growth when altered the temperature to $30^{\circ} \mathrm{C}$. The upper limit of the temperature tolerance for LE- 1 was $35^{\circ} \mathrm{C}$ for 12 days where the revival of growth (7.5 $\mathrm{mm}$ per day) was observed after exposing to the optimum temperature of $25^{\circ} \mathrm{C}$. Whereas, the mycelium was completely killed at an exposure of 7 days at $38^{\circ} \mathrm{C}$, where there was no revival of growth.
In conclusion, Experimental findings of comparative evaluation of culture media, $\mathrm{pH}$ and temperatures for mycelial growth of one each of wild strains of Schizophyllum commune and Lentinula edodes concluded that PDA medium with a $\mathrm{pH}$ range of 5.0 to 8.0 at a temperature of $30{ }^{\circ} \mathrm{C}$ and MEA medium with a pH range of 4.5 to 6.5 at a temperature of $25{ }^{\circ} \mathrm{C}$ gave the better growth of mycelium for Schizophyllum commune and Lentinula edodes respectively and appeared to better in maintenance of pure culture. This investigation will help for the selection of culture media, $\mathrm{pH}$ and optimum temperature for the maintenance of genetic materials.

\section{References}

Arpita, M.T., and Bhupendra, N.T. 2013. Biochemical constituents of a wild strain of Schizophyllum commune isolated from Achanakmar-Amarkantak Biospehere Reserve (ABR), India. World J Microbiol Biotechnol 29, 14311442. 
Hem Lata, and Sharma, S.R. 2012. Evaluation of culture conditions for the vegetative growth of different strains of Lentinula edodes. Mushroom Research 21(1), 3542.

Martnexflores, H.E., Mayacorts, D.C., Figueroacardenas, J.D., Gamicaromo, M.G., and Poncesaavedra, J. 2009. Chemical composition and physicochemical properties of shiitake mushroom and high fibre products. Journal of Food 7(1), 7-14.

Neha, J., and Bharat, P. 2012. Medicinal mushrooms: A blessing to the mankind. Asian J of Research in Pharm Sci 2(1), 12-15.

Philippoussis, A.N., Diamantopoulou, P.A., and Zervakis, G.I. 2003. Correlation of the properties of several lignocellulosic substrates to the crop performance of the shiitake mushroom Lentinula edodes. World J of Microb \& Biotech 19, 551-557.

Sharma, S.R., Kumar, S., and Sharma, V.P. 2006. Physiological requirement for cultivation of Malaysian strain of shiitake, Lentinula edodes. J Mycol Pl Pathol 36(2), 149-152.

Singh, S.K., Upadhyay, R.C., and Verma, R.N. 2000. Physico-chemical preferences for efficient mycelial colonization in edible mushrooms. Mushroom Research 9(2), 85-89.

Tnglet, R.S., Song, M., Hensen, C.L., and Hwang, S. 2006. Cultivation of Lentinula edodes mycelia using whey permeate as an alternative growth substrate. J Dairy Science 89, 11131115.

\section{How to cite this article:}

Praveen Kumar Reddy, B., A. Uma Rajashekhar, P. Harikrishna and Lavanya, A.V.N. 2017. Cultural and Physiological Studies on Wild Mushroom Specimens of Schizophyllum commune and Lentinula edodes. Int.J.Curr.Microbiol.App.Sci. 6(7): 2352-2357.

doi: https://doi.org/10.20546/ijcmas.2017.607.278 